\title{
Real time chemical characterization of local and regional nitrate aerosols
}

\author{
M. Dall'Osto ${ }^{1,}{ }^{*}$, R. M. Harrison ${ }^{1}$, H. Coe ${ }^{2}$, P. I. Williams ${ }^{2}$, and J. D. Allan ${ }^{2}$ \\ ${ }^{1}$ National Centre for Atmospheric Science, Division of Environmental Health \& Risk Management, School of Geography, \\ Earth \& Environmental Sciences, University of Birmingham, Edgbaston, Birmingham B15 2TT, UK \\ ${ }^{2}$ National Centre for Atmospheric Science, School of Earth, Atmospheric \& Environmental Sciences, The University of \\ Manchester, Simon Building Oxford Road, Manchester M13 9PL, UK \\ * currently at: School of Physics \& Centre for Climate \& Air Pollution Studies, Environmental Change Institute National \\ University of Ireland, Galway, Ireland
}

Received: 4 August 2008 - Published in Atmos. Chem. Phys. Discuss.: 17 November 2008

Revised: 7 April 2009 - Accepted: 20 May 2009 - Published: 9 June 2009

\begin{abstract}
Nitrate aerosols make a very major contribution to $\mathrm{PM}_{2.5}$ and $\mathrm{PM}_{10}$ in western Europe, but their sources and pathways have not been fully elucidated. An Aerosol Time-of-Flight Mass Spectrometer (ATOFMS) and a Compact Time of Flight Aerosol Mass Spectrometer (C-ToFAMS) were deployed in an urban background location in London, UK, collecting data as part of the REPARTEE-I experiment. During REPARTEE-I, daily $\mathrm{PM}_{10}$ concentrations ranged up to $43.6 \mu \mathrm{g} \mathrm{m}^{-3}$, with hourly nitrate concentrations (measured by AMS) of up to $5.3 \mu \mathrm{g} \mathrm{m}^{-3}$. The application of the ART-2a neural network algorithm to the ATOFMS data characterised the nitrate particles as occurring in two distinct clusters (i.e. particle types). The first (33.6\% of particles by number) appeared to be locally produced in urban locations during nighttime, whilst the second (22.8\% of particles by number) was regionally transported from continental Europe. Nitrate in locally produced aerosol was present mainly in particles smaller than $300 \mathrm{~nm}$, whilst the regional nitrate presented a coarser mode, peaking at $600 \mathrm{~nm}$. In both aerosol types, nitrate was found to be internally mixed with sulphate, ammonium, elemental and organic carbon. Nitrate in regional aerosol appeared to be more volatile than that locally formed. During daytime, a core of the regionally transported nitrate aerosol particle type composed of organic carbon and sulphate was detected.
\end{abstract}

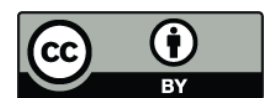

Correspondence to: R. M. Harrison (r.m.harrison@bham.ac.uk)

\section{Introduction}

Nitrate aerosol is a major component of the total aerosol mass in western Europe. It is formed chemically in the atmosphere from the precursor species ammonia $\left(\mathrm{NH}_{3}\right)$ and nitric acid $\left(\mathrm{HNO}_{3}\right)$. Sources of ammonia include agricultural sources such as livestock housing and the storage and spreading of manures as well as oceans, biomass burning, crops and soil (Bouwman et al., 1997). Typical sources of nitrogen oxides $\left(\mathrm{NO}_{\mathrm{x}}\right)$, which are the main precursor of nitric acid, include fossil fuel combustion, soils, biomass burning and lighting. During the day, $\mathrm{NO}_{\mathrm{x}}$ is oxidized by $\mathrm{OH}$ to form $\mathrm{HNO}_{3}$, whilst during night time the $\mathrm{NO}_{3}$ radical (which is photolysed during the day) may be formed by reaction between $\mathrm{NO}_{2}$ and ozone and can be converted to nitric acid via its thermal equilibrium with $\mathrm{N}_{2} \mathrm{O}_{5}$ (Carslaw et al., 1997; Brown et al., 2005). Sub-micrometre nitrate aerosol is predominantly present in the form of ammonium nitrate $\left(\mathrm{NH}_{4} \mathrm{NO}_{3}\right)$, a semi-volatile compound.

The equilibrium between ammonium nitrate and its gaseous precursors is relatively well understood. The gasaerosol partitioning of nitrate depends strongly on the availability of its precursor gases and on the ambient conditions. Atmospheric ammonia may also be neutralized irreversibly by sulphuric acid $\left(\mathrm{H}_{2} \mathrm{SO}_{4}\right)$ to form ammonium sulphate $\left(\left(\mathrm{NH}_{4}\right)_{2} \mathrm{SO}_{4}\right)$. If excess $\mathrm{NH}_{3}$ is available then it may combine with $\mathrm{HNO}_{3}$ to form $\mathrm{NH}_{4} \mathrm{NO}_{3}$ (Allen et al., 1989).

Coarse particle nitrate also arises from the surface reaction of nitric acid with sea salt aerosol. The coarse mode of nitrate typically exhibits a mass median diameter of ca $2.5 \mu \mathrm{m}$

Published by Copernicus Publications on behalf of the European Geosciences Union. 
(Abdalmogith et al., 2006b). An analysis of air mass back trajectories clearly indicates the importance of long-range transport as a source of nitrate in the UK atmosphere (Abdalmogith and Harrison, 2005). However, a careful analysis of the spatial distribution of measured concentrations of nitrate in air reveals a clear urban excess in London over the surrounding region (Abdalmogith et al., 2006a).

Airborne particulate matter (PM) has environmental, health and climate effects. Despite the fact that research on PM is intense, much remains to be learned about PM composition and physico-chemical properties. Nitrate aerosol influences global climate. A number of modeling studies have identified nitrate and ammonium as significant components of aerosol load (Adams et al., 2001), but most global models of direct aerosol radiative forcing do not directly account for ammonium nitrate. Other studies have shown that increases in $\mathrm{NO}_{\mathrm{x}}$ emissions could produce sufficient nitrate aerosol to off-set the expected decline in sulphate radiative forcing (Liao et al., 2004, 2006). Moreover, ammonium nitrate aerosol exhibits a large hygroscopic growth factor, and its high water uptake for a given relative humidity could contribute significantly to the total magnitude of the aerosol direct radiative forcing (Bauer et al., 2007). Aircraft measurements made above the Po Valley, Italy, have previously shown that ammonium nitrate can dominate the submicrometre aerosol composition on a regional scale making a significant contribution to the regional radiative budget (Crosier et al., 2007).

Recently, nitrate aerosol has attracted more attention not only in relation to global effects, but also in relation to local air quality. In a UK site comparison of data for days with $\mathrm{PM}_{10}$ above the EU 24-h Limit Value of $50 \mu \mathrm{g} \mathrm{m}^{-3}$ with data from all days, the component showing the greatest ratio between high pollution days and all days was fine particle nitrate (Harrison et al., 2003; 2004; Yin and Harrison, 2008). Also recently, the contribution of nitrate-rich regionally transported aerosol to episodes breaching the daily Limit Value was highlighted (Charron et al., 2007). Nitrate aerosol, with its strongly bound water, accounted for on average $39 \%$ of $\mathrm{PM}_{10}$, and $46 \%$ of $\mathrm{PM}_{2.5}$ during episode conditions where the $\mathrm{PM}_{10}$ concentrations exceeded the EU 24-h Limit Value (Yin and Harrison, 2008). In Utah (USA), $\mathrm{PM}_{2.5}$ concentrations were dominated by the formation of ammonium nitrate, accounting for over $50 \%$ of the non-refractory aerosol matter throughout the study and $80 \%$ on the highest pollution days (Silva et al., 2007). These findings suggest that international abatement of secondary aerosol precursors may be the most effective measure to fulfill the requirements of the European Directive 1999/30/CE by lowering the regional background. In spite of its importance, there have been few studies of the formation of nitrate aerosol in the nocturnal atmosphere. Moreover, there is very little information on the chemical composition and the mixing state of nitrate aerosol. Brown et al. (2006) for example reported aircraft measurements showing that the $\mathrm{N}_{2} \mathrm{O}_{5}$ uptake coefficient on aerosol particles is highly variable and depends strongly on aerosol composition. Brown et al show that the uptake coefficient of $\mathrm{N}_{2} \mathrm{O}_{5}$ to a mixed sulphate-organic aerosol is very dependent on the sulphate content and its acidity.

In recent years aerosol mass spectrometry has become available as a powerful tool for the on-line chemical characterization of individual aerosol particles (Murphy, 2007; Noble and Prather, 2000) or small aerosol ensembles (Canagaratna et al., 2007). Here we report the measurement and characterization of aerosol particles detected in an urban background location in London by using two types of on-line aerosol mass spectrometers, i.e. C-ToF-AMS and ATOFMS, as well as a variety of other on-line aerosol instrumentation.

This paper investigates the characteristics of nitratecontaining aerosols detected in an urban background location, including aerosols locally produced and regionally transported. Moreover, their mass loading, size distributions, mixing state and diurnal variation will be presented and discussed.

\section{Experimental}

\subsection{Aerosol sampling}

Sampling took place in Regents Park, one of the Royal Parks of London between the 4 and the 22 October 2006. Regents Park is located in the northern part of central London. The park has an outer ring road called the Outer Circle $(4.3 \mathrm{~km})$ and an inner ring road called the Inner Circle. Apart from two link roads between these two, the park is reserved for pedestrians. The 487 acre (about $2 \mathrm{~km}^{2}$ ) park is mainly open parkland. The sampling site chosen was inside the inner circle, in an open area usually reserved for parking and gardening purposes. All the instruments were housed in a mobile laboratory.

The site was operated as part of a UK experiment called REPARTEE-I (Regent's Park and Tower Environmental Experiment) aiming to study atmospheric chemical processes, and particularly those affecting atmospheric aerosol, in London. Other papers are also submitted (Dall'Osto et al., 2009) or in preparation.

Meteorological, gas-phase and aerosol measurements were conducted from the top of a $10 \mathrm{~m}$ high tower constructed on site. To minimize sampling losses, air was drawn down a vertical sample pipe approximately $150 \mathrm{~mm}$ in diameter, which allowed air to be drawn from above the surrounding tree line. Air was sub-sampled from the main sample flow in an iso-kinetic manner through a $40 \mathrm{~mm}$ diameter stainless steel pipe with a knife edge forward facing tip, and was taken via a gentle $90^{\circ}$ bend into the air conditioned mobile laboratory. At $293 \mathrm{~K}$ and assuming a gas density of $1.2 \mathrm{~kg} \mathrm{~m}^{-3}$, the Reynolds number for the sub-sample is $\sim 1,400$ indicating laminar flow. Pui et al. (1987) derived transport efficiency for particles travelling through such a 
bend based on a fit to data. Using their fit suggests that particles as large as $20-30 \mu \mathrm{m}$ will be transmitted with nearly $100 \%$ efficiency. A similar result is obtained from the simplified Crane and Evans (1977) model. It must be stressed that these fits and models are approximations and can only be used as such. They do however suggest that large particles will be sampled efficiently by the sub-sampling system.

Local meteorological conditions were measured by humidity and temperature probes, and a sonic anemometer which measured the 3-D wind field at the sampling site.

\subsection{Instrumentation}

Two on-line aerosol mass spectrometers were operated at the measurement site, an ATOFMS (Model 3800-100, TSI, Inc.) and a C-ToF-AMS (Aerodyne Research, Inc.).

The ATOFMS collects bipolar mass spectra of individual aerosol particles. Ambient aerosol is focused into a narrow particle beam for sizes between $100 \mathrm{~nm}$ and $3 \mu \mathrm{m}$. Using a 2-laser velocimeter particle sizes are determined from particle velocity after acceleration into the vacuum. In addition, the light scattered by the particles is used to trigger a pulsed high power desorption and ionization laser $(\lambda=266 \mathrm{~nm}, 1 \mathrm{~mJ} / \mathrm{pulse})$ which evaporates and ionizes the particle in the centre of the ion source of a bipolar reflectron ToF-MS. Thus, a positive and negative ion spectrum of a single particle are obtained. The mass spectrum is qualitative in that the intensities of the mass spectral peaks are not directly proportional to the component mass but are dependent on the particle matrix, the coupling between the laser and the particle and the shot to shot semi-variability of the laser. However, the ATOFMS can provide quantitative information on particle number as a function of composition; providing a measure of all particle components and can be used to assess mixing state. The ATOFMS provides information on the abundance of different types of aerosol particles as a function of particle size with high time resolution (Suess and Prather, 1999).

The Aerodyne Time-of-Flight Aerosol Mass Spectrometer (C-ToF-AMS) (Drewnick et al., 2005) focuses aerosol particles in the size range $50-600 \mathrm{~nm}$ quantitatively onto a hot surface $\left(\sim 600^{\circ} \mathrm{C}\right)$ using an aerodynamic lens assembly (Jayne et al., 2000). Smaller and larger particles are also collected with lower efficiency. Non-refractory particle components flashevaporate on the hot surface; the evolving vapour is electron impact $(70 \mathrm{eV})$ ionized and the ions are transported into an orthogonal extraction ToF-MS for mass analysis. Particle size information is obtained by chopping the particle beam and collecting mass spectra as a function of particle flight time. The instrument provides 5-min averages of mass concentrations of the non-refractory aerosol components as well as species-resolved size distributions. A detailed description of the instrument and its operation is given in Drewnick et al. (2005). The instrument provides quantitative mass loading information on sub-micrometre non refractory compo- nents using a well characterised series of calibrations and error estimations (Jimenez et al., 2003; Allan et al., 2003, 2004).

The AMS was run under standard operating conditions and calibrated using $350 \mathrm{~nm}$ monodisperse ammonium nitrate particles, selected using a DMA. Based on the fact that the recorded composition was always a mixture of nitrate, sulphate and organics, a collection efficiency of around 0.5 was expected, based on the characterisation work of Matthew et al. (2008). This was validated by deriving a total particulate volume concentration (assuming the component densities reported by Cross et al., 2008) and comparing with a volume concentration derived from a differential mobility particle sizer (DMPS, Williams et al., 2000), assuming spherical particles and only including particles up to $600 \mathrm{~nm}$ in mobility diameter (this is to eliminate particles of an aerodynamic size too great to be effectively measured using the AMS). When compared, the AMS-derived volume concentration is either in good agreement or slightly less than the DMPS-derived equivalent. Given that a certain fraction of the submicron particulate volume (such as elemental carbon) is not detected by the AMS, this is the expected behaviour. A collection efficiency greater than 0.5 would result in periods where the MS-derived volume concentration would exceed that of the DMPS. Although it shows that the CE could not have exceeded 0.5 for all of the time, it is still possible that $\mathrm{CE}$ was temporally variable and exceeded 0.5 in high nitrate conditions (Matthew et al., 2008).

In addition to the aerosol mass spectrometers a variety of on-line aerosol instruments was deployed to measure different physical characteristics of the ambient aerosol. A Multi-Angle Absorption Photometer (MAAP, Thermo Electron) (Petzold and Schonlinner, 2004) was used to measure 1-min averages of the ambient black carbon concentrations. Moreover, (R\&P) Dichotomous Partisol-Plus Model 2025 sequential air samplers, fitted with $\mathrm{PM}_{10}$ inlets were deployed for collecting fine $\left(\mathrm{PM}_{0-2.5}\right)$ and coarse $\left(\mathrm{PM}_{2.5-10}\right)$ fractions. A number of other instruments were used during the REPARTEE-I campaign but are not listed here since their data are not discussed in this paper.

\subsection{Data analysis}

The ATOFMS was deployed at Regents Park for 19 days, between 4 October 2006 at 17:00 and 22 October 2006 at 23:00. In total, 153595 particles were hit by the ATOFMS. The TSI ATOFMS dataset was imported into YAADA (Yet Another ATOFMS Data Analyzer) and single particle mass spectra were grouped with Adaptive Resonance Theory neural network, ART-2a (Song et al., 1999). The parameters used for ART-2a in this experiment were: learning rate 0.05, vigilance factor 0.85 , and iterations 20 . Further details of the parameters can be found elsewhere (Dall'Osto and Harrison, 2006; Rebotier and Prather, 2007). An ART-2a area matrix (AM) of a particle cluster represents the average intensity for 


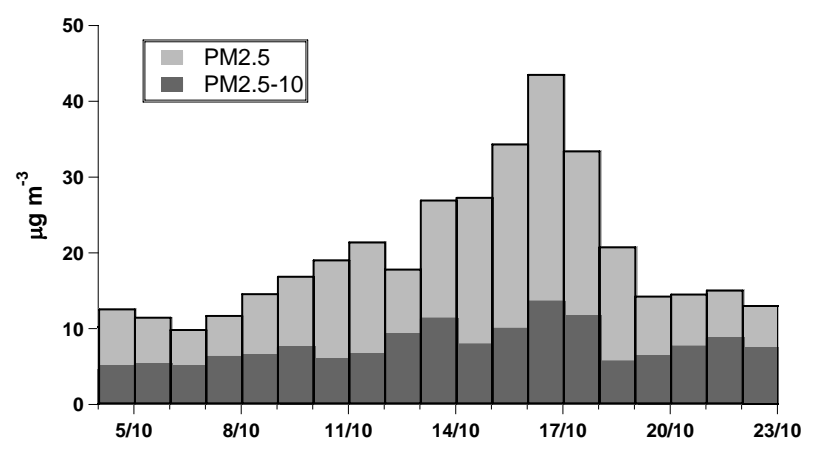

Fig. 1. $\mathrm{PM}_{2.5}, \mathrm{PM}_{2.5-10}$ and $\mathrm{PM}_{10}$ daily mean concentrations during REPARTEE.

each $m / z$ for all particles within a group. An ART-2a AM therefore reflects the typical mass spectrum of the particles within a group. The ART-2a algorithm generated 306 clusters used to describe the dataset. By manually merging similar clusters (Dall'Osto and Harrison, 2006), the total number of clusters describing the whole database was reduced to about 20. Common particle types including sea salt, soil dust, biomass burning and lubricating oil were attributed to other sources. However, the objective of this paper is not to present an overview of all the ATOFMS classes, but to focus on the nitrate containing aerosol which accounted for about $65 \%$ of the total particles classified.

\section{Results and discussion}

\subsection{Overview}

The weather during the field study was characterized by unusually warm conditions for the month of October in the UK (temperature $14.1 \pm 2.8^{\circ} \mathrm{C}$, relative humidity $82.6 \pm 10.7 \%$; mean \pm 1 s.d. of hourly data) with several small rainfall events (about a dozen). Back trajectories of the air masses arriving at the measurement site were calculated for 00:00 and 12:00 for each day of the campaign, depicting the path taken by the air mass reaching the sampling site over the previous five days. The back trajectories were run using the on-line HYSPLIT model (Draxler and Rolph, 2003) developed by the National Oceanic and Atmospheric Administration (NOAA). The predominant origin of air masses arriving at the receptor was westerly, with Atlantic air masses not strongly influenced by anthropogenic pollution.

However, during two periods, air masses arriving at our site had previously travelled from the east over European industrialized regions. Air masses arriving from mainland Europe (mainly France and Poland) were detected on 10-11 October 2006 and on 14-20 October 2006. These two main periods were characterised by the highest particulate mass loading, as shown in Fig. 1. $\mathrm{PM}_{10}$ reached a maximum con-
Table 1. Summary of the Nitrate ATOFMS classes obtained using ART-2a, detected during the REPARTEE-I Experiment.

\begin{tabular}{lll}
\hline ATOFMS particle types & Nitrate types & $\%$ \\
\hline Local Nitrate & Nitrate 1 & 33.6 \\
LRT Nitrate & Nitrate 2 & 22.8 \\
LRT Nitrate core & & 7.9 \\
others & - & 35.7 \\
\hline
\end{tabular}

centration of $43.6 \mu \mathrm{g} \mathrm{m}^{-3}$ on 16 October 2006. Almost $70 \%$ of it was in the $\mathrm{PM}_{2.5}$ fraction. This study is consistent with earlier findings, where episode days with $\mathrm{PM}_{10}$ exceeding $50 \mu \mathrm{g} \mathrm{m}^{-3}$ were linked with regional (although not necessarily continental) transport of secondary pollutants (Charron et al., 2007; Yin and Harrison 2008).

\subsection{Nitrate aerosols}

Of the 20 or so clusters generated from the ATOFMS data, the main particle types were characterised by strong signals at $\mathrm{m} / z-46$ and $\mathrm{m} / z-62$ due to nitrate $\left(\left[\mathrm{NO}_{2}\right]^{-}\right.$and $\left[\mathrm{NO}_{3}\right]^{-}$ respectively), representing about $65 \%$ of the particles classified. Table 1 shows two nitrate-containing particle types which were named according to their inferred origins, the former called local nitrate $(33.6 \%$ of the total), the latter called LRT (Long Range Transport, $30.7 \%$ of the total). The reasons for assignment to these classes are based on their temporal trends as outlined below. It is recognised that due to the semi-volatility of ammonium nitrate, nitrate will transfer between gas and particle phases. The particle names consequently refer more to the origins of core particles upon which nitrate condenses than necessarily to the source of the nitrate ion itself. Additionally, it is important to note that any particle clustering algorithm will seek to identify discrete particle types and will fail to deal adequately with situations in which a continuum of evolving composition between two or more particle types occurs.

Nitrate mass loading concentrations detected over time by the AMS during the REPARTEE-I campaign are shown in Fig. 2a. It can be seen that the majority of the nitrate was sampled during the periods previously identified as associated with episodes of long range transport. The black line shows the temporal trends ( $1 \mathrm{~h}$ resolution) of the sum of the two ATOFMS nitrate particle types (local and LRT). Although the AMS measures the particle mass loading ( $\mu \mathrm{g}$ $\mathrm{m}^{-3}$ ) whilst the ATOFMS temporal trend is reported in number of particles detected (ATOFMS counts per hour), the correlation is very good $\left(R^{2}=0.75\right)$.

The temporal trends of the 2 ATOFMS nitrate particle types are presented in Fig. 2b. Although the trends appear similar, the local nitrate presented a unique temporal trend, 

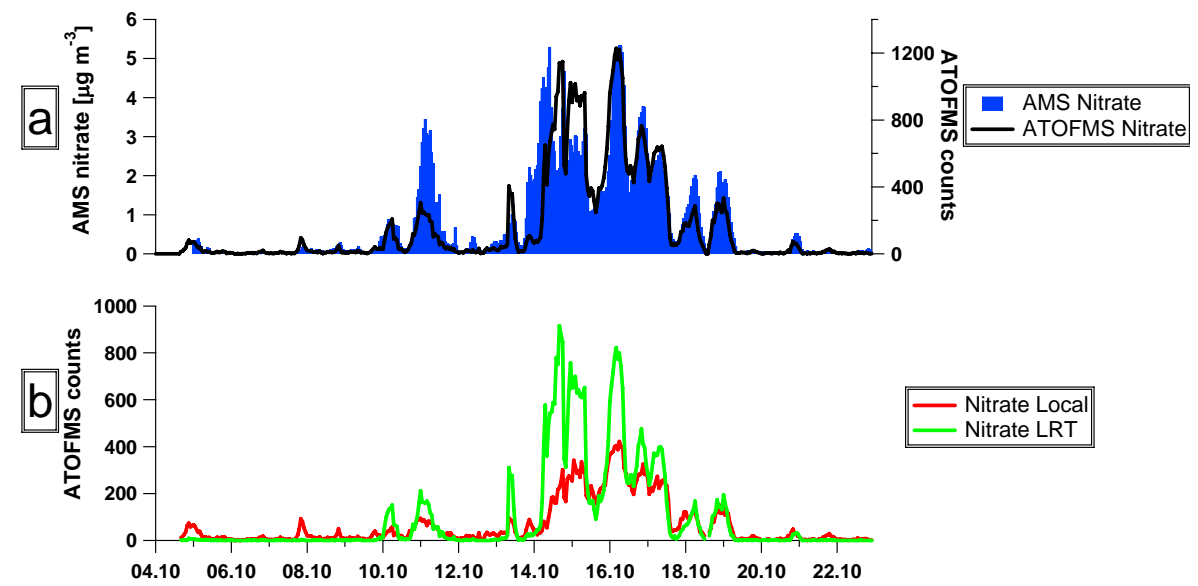

Fig. 2. (a) Total nitrate (Local and LRT) ATOFMS temporal trends (1 h resolution) and AMS nitrate mass loading (b) Local and LRT ATOFMS temporal trends ( $1 \mathrm{~h}$ resolution).

especially during the first part of the field study. ATOFMS local nitrate (red line) presented a marked maximum peak during night time (especially between 23:00 and 06:00) on 4, $7,8,9,12,13$ and 22 October.

Figure 3a shows the ART-2a average spectra of the ATOFMS local nitrate particle type. The negative spectrum is dominated by the presence of nitrate $(\mathrm{m} / \mathrm{z}$ at -46 and -62$)$ and sulphate $\left(\mathrm{m} / z-97\left[\mathrm{HSO}_{4}^{-}\right]\right)$. The peak at $\mathrm{m} / z-125$ is due to $\left[\mathrm{H}\left(\mathrm{NO}_{3}\right)_{2}^{-}\right]$. The positive AM shows a strong peak at $\mathrm{m} / \mathrm{z} 39$. The peak at $\mathrm{m} / \mathrm{z} 39$ is often associated with potassium $[\mathrm{K}]^{+}$, to which the ATOFMS is especially sensitive, but it could also be due to an organic fragment $\left[\mathrm{C}_{3} \mathrm{H}_{3}\right]^{+}$(Silva and Prather 2000). The complete absence of common $\mathrm{m} / z$ due to potassium (i.e. $m / z, 113\left[\mathrm{~K}_{2} \mathrm{Cl}\right]^{+}$or $m / z 213\left[\mathrm{~K}_{3} \mathrm{SO}_{4}\right]^{+}$) and ratio between $\mathrm{m} / \mathrm{z}, 39$ and $\mathrm{m} / \mathrm{z}, 41$ of about 19 (the isotopic ratio ${ }^{39} \mathrm{~K} /{ }^{41} \mathrm{~K}$ is 13.28 ) strongly suggest that the $m / z 39$ peak is not due to potassium alone. Most likely, there is also a contribution from an organic ion, probably $\left[\mathrm{C}_{3} \mathrm{H}_{3}\right]_{\text {. }}^{+}$Smaller peaks due to ammonium $\left(\mathrm{m} / \mathrm{z} 18\left[\mathrm{NH}_{4}\right]^{+}\right)$and elemental carbon $\left(\mathrm{m} / \mathrm{z} 36\left[\mathrm{C}_{3}\right]^{+}, 48\left[\mathrm{C}_{4}\right]^{+}\right.$and $\left.60\left[\mathrm{C}_{5}\right]^{+}\right)$should also be noted. Local nitrate was also detected during periods when the LRT nitrate was detected, but those will be addressed later. Specific periods of time characterized only by the presence of the local nitrate particle type are considered first.

The average size-resolved mass distributions of nitrate, organic matter, ammonium and sulphate detected by the AMS are shown in Fig. 4a for periods when the ATOFMS local nitrate particle type was observed. This was calculated by taking only selected time periods between 23:00 and 06:00 when the ATOFMS local nitrate particle type was at its maximum number concentration. Figure $4 \mathrm{c}$ shows the aerosol mass distribution on a logarithmic scale. It is clear that about half of the mass of this nitrate aerosol is distributed in vacuum aerodynamic diameters $\left(\mathrm{D}_{v a}\right.$, aerodynamic diameters measured in the free molecular regime) smaller than $350 \mathrm{~nm}$.

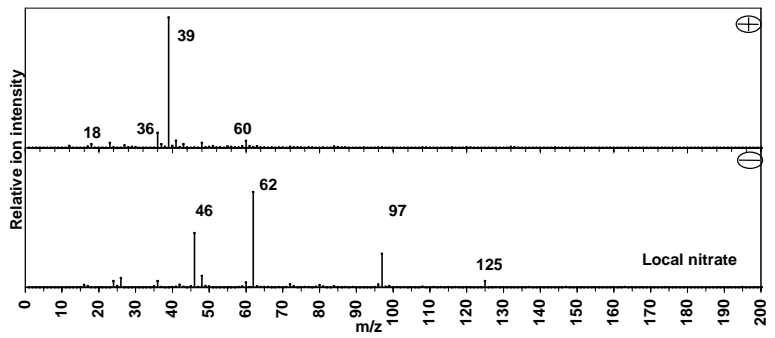

(a)

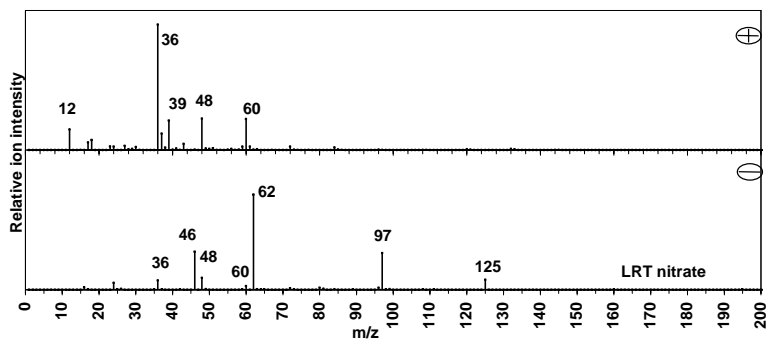

(b)

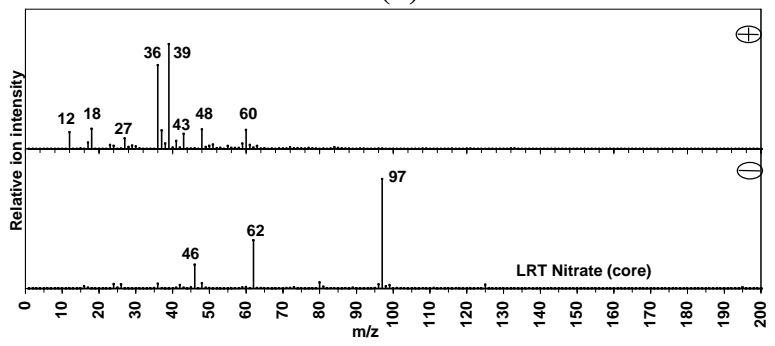

(c)

Fig. 3. Positive (+) and negative (-) ART-2a spectra of particles attributed to (a) Local Nitrate, (b) LRT Nitrate and (c) LRT Nitrate (core). 


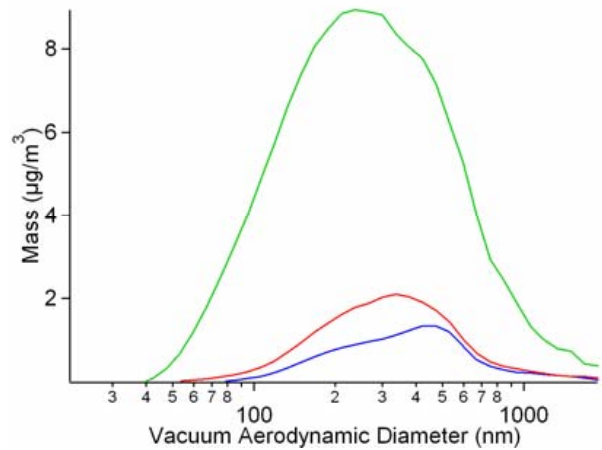

(a)

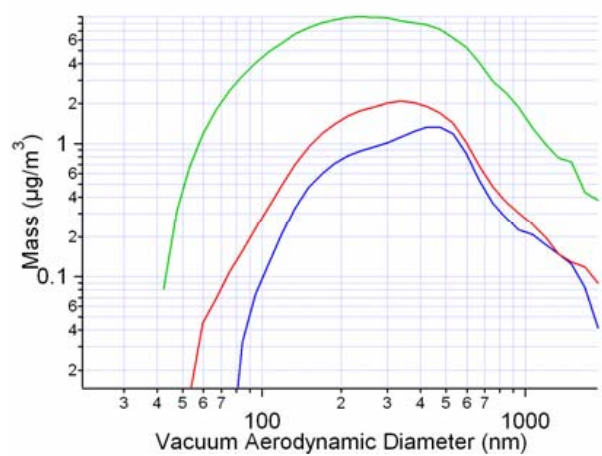

(c)

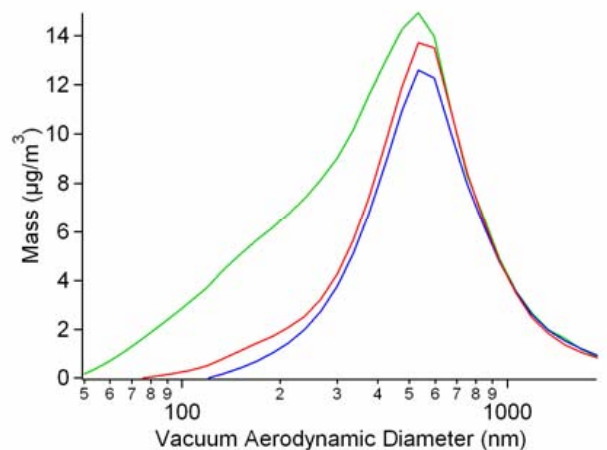

(b)

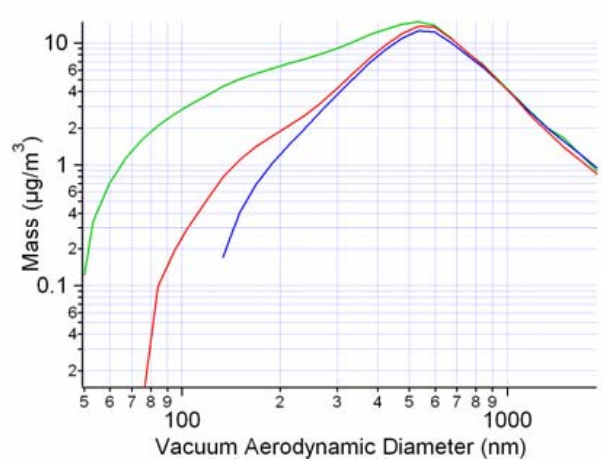

(d)

Fig. 4. Average size-resolved AMS mass loading $\left(\mu \mathrm{g} / \mathrm{m}^{3}\right)$ for organic (green), sulphate (red), and nitrate (blue) components for (a) and (c) selected time periods between 23:00 and 06:00 when the ATOFMS local nitrate particle type was at its maximum number concentration and (b) and (d) periods when the ATOFMS LRT nitrate particle type was detected. Figures 4c and d, are the same as (a) and (b) but with the Y-axes on a logarithmic scale. The C-ToF-AMS measures particle size aerodynamically in the free molecular regime, delivering the so-called vacuum aerodynamic diameter $\left(\mathrm{D}_{v a}\right)$.

This is consistent with the scaled ATOFMS number size distribution of the local nitrate shown in Fig. 5, peaking in the smallest detectable size at an aerodynamic diameter $\left(\mathrm{D}_{a}\right)$ of about $200 \mathrm{~nm}$. ATOFMS number size distribution were calculated by scaling the ATOFMS counts with SMPS and APS data (Qin et al., 2006) and they are meant to provide only qualitative information. The temporal trend of this nitrate particle type, along with its size distributions, suggests that it is formed locally within London. Particle volume distributions have been calculated and are also shown in Fig. 5 . Number concentrations of these particles typically peaked at night, consistent with semi-volatile nitrate condensing on locally emitted particles at times of lower temperature and higher relative humidity. Nitrate formation through heterogeneous reactions of the $\mathrm{NO}_{3}$ free radical may also contribute.

The second type of ATOFMS nitrate particle accounted for about $30 \%$ of the total particles sampled during the REPARTEE-I, representing about $50 \%$ of the total nitrate containing aerosols detected by the ATOFMS. The LRT ni- trate particle type was detected only during periods affected by air masses which had originated in continental Europe and then transported regionally over England. Figure 3b shows the ART-2a mean spectra of the LRT nitrate particle type. The negative spectrum is similar to that described for the local nitrate type, with dominant peaks due to nitrate and sulphate. However, a much stronger signature reflecting elemental carbon $(\mathrm{m} / \mathrm{z}-36,-48$ and -60$)$ should be noted. The distinct elemental carbon signature is seen also in the positive spectrum, showing the strongest signal at $\mathrm{m} / \mathrm{z} 36$. The peak at $\mathrm{m} / \mathrm{z} 39$, along with minor peaks at, $\mathrm{m} / \mathrm{z} 27,37$ and 43 $\left(\left[\mathrm{C}_{2} \mathrm{H}_{3}\right]^{+},\left[\mathrm{C}_{3} \mathrm{H}\right]^{+}\right.$and $\left[\mathrm{C}_{2} \mathrm{H}_{3} \mathrm{O}\right]^{+}$respectively) shows that the LRT nitrate is internally mixed also with organic carbon.

The average size-resolved mass distribution of nitrate particles detected by the AMS is shown in Fig. $4 b$, and on a logarithmic scale on Fig. 4d. This was calculated by taking only the nitrate aerosol mass collected by the AMS during the period 14-19 October. The size distribution of the nitrate aerosol detected during this period is very different from that 
characterising the local nitrate type. The size distribution for LRT nitrate particles peaks at a $\mathrm{D}_{v a}$ of about $600 \mathrm{~nm}$ in the accumulation mode, with very little aerosol mass distributed in particles smaller than a $\mathrm{D}_{v a}$ of $300 \mathrm{~nm}$. This is consistent with previous studies utilizing the AMS where the temporal variations of the size distributions of the accumulation mode components suggested internal mixing with sulphate and organic matter which was attributed to a regional background mode (Allan et al., 2003; Alfarra et al., 2004). Data from the ATOFMS and the AMS suggest that the LRT particle type is internally mixed with sulphate, ammonium and both elemental and organic carbon.

Furthermore, unique information on the diurnal variation of this particle type can be found in the ATOFMS data. Figure 6a shows a time period during the LRT episode (15-17 October 2006) and combines the data shown in Fig. 2a and b at high time resolution. Figure $6 \mathrm{~b}$ shows the diurnal temporal variation of temperature and relative humidity. The diurnal variation of the LRT nitrate particle type, (seen by both particle mass spectrometers) confirms the strong volatility of the nitrate, with loss to the gas phase during daytime due to the higher temperature. This diurnal behaviour is not shown by sulphate, which was also elevated in concentration, clearly suggesting an enhanced volatilisation of nitrate during daytime. This suggests that the involatile core particles are longrange transported, but that nitrate cycles between the gas and particle phase according to atmospheric conditions and that its formation may be relatively local. Another specific type of particle was detected only during those daytime periods, and found to be anti-correlated with the ATOFMS LRT nitrate particle type. We believe this particle type is the nonvolatile core of the LRT nitrate particle type which is consequently named "Nitrate LRT core". The ATOFMS scaled size distribution of Nitrate LRT core peaks at about $300 \mathrm{~nm}$. ATOFMS scaled particle number size distributions are not quantitative, but they provide some important qualitative information. Figure $4 \mathrm{~b}$ shows that the core of the Nitrate LRT particle type presents a smaller size distribution in comparison to the nitrate LRT itself, consistent with the evaporation of material during daytime. The fact that the peak number counts of the two particle types are very similar supports this interpretation.

Figure 3c shows the ART-2a spectra of the core of the ATOFMS LRT nitrate particle type. Smaller peaks due to nitrate can be seen in the negative spectrum, whilst a stronger peak due to sulphate relative to nitrate (in comparison to the LRT nitrate type, Fig. 3b) should be noted. Moreover, the peak at $m / z-125\left[\mathrm{H}\left(\mathrm{NO}_{3}\right)_{2}\right]$ is almost undetectable, confirming the lesser presence (but not absence) of nitrate species in the Nitrate LRT core particle type. The positive spectrum shows the presence of ammonium $(\mathrm{m} / \mathrm{z}, 18)$, organic carbon $(\mathrm{m} / \mathrm{z}, 27,39$ and 43$)$ and elemental carbon $(\mathrm{m} / \mathrm{z}, 12,36$, 48,60 ). The peak at $\mathrm{m} / \mathrm{z} 39$ is much stronger in the core of the Nitrate LRT particle spectrum than in the nighttime form. An overview the differences in spectra for the LRT ni-
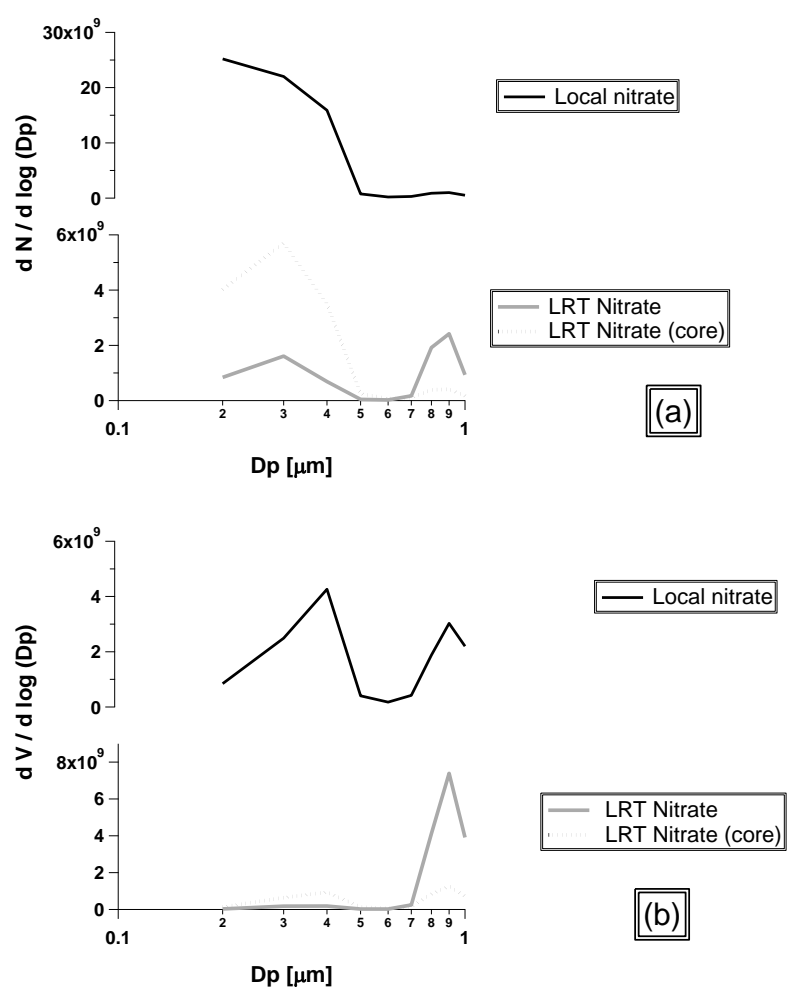

Fig. 5. ATOFMS scaled size distributions in Number (dN/dlogDp where $N$ is the scaled total number of particles attributed to the specific ATOFMS cluster) and Volume (d V/d log Dp $\left[\mu \mathrm{m}^{3} \mathrm{~cm}^{-3}\right]$. The ATOFMS measures particle size aerodynamically, delivering the particle aerodynamic diameter $\left(\mathrm{D}_{p}\right)$.

trate and its core particle can be seen in Fig. 7, which shows the subtraction spectrum for the LRT nitrate minus its core (Fig. 3c minus Fig. 3b). The positive ion spectrum for Nitrate LRT is enhanced in elemental carbon $(\mathrm{m} / \mathrm{z} 12,36,48$ and 60), whilst the negative is enriched as expected in nitrate peaks $(\mathrm{m} / \mathrm{z}-46,-62$ and -125$)$. The key difference of the core of Nitrate LRT in the spectra in comparison to the nighttime nitrate form is the strong presence of $\mathrm{m} / \mathrm{z} 39$ in the positive spectrum and $m / z-97$ in the negative one indicating relatively more organic carbon, potassium and sulphate in the particle core. However, suprisingly, more elemental carbon is found during nighttime. A commonly cited limitation of laser desorption/ionization (LDI) single particle mass spectrometry is that the LDI process is heavily influenced by particle size, morphology and matrix composition since these will influence energy transfer from the laser beam to the particle, vaporisation of the particle and ion formation in the vaporisation plume (Mansoori et al., 1994; Carson et al., 1997; Thomson et al., 1997; Reilly et al., 2000; Schoolcraft et al., 2001). Progress has been made in quantifying atomic species using high laser powers. For example, Spencer et al. (2006) were able to chemically quantify fresh small Elemental Carbon/Organic Carbon particles, but in particles smaller than 

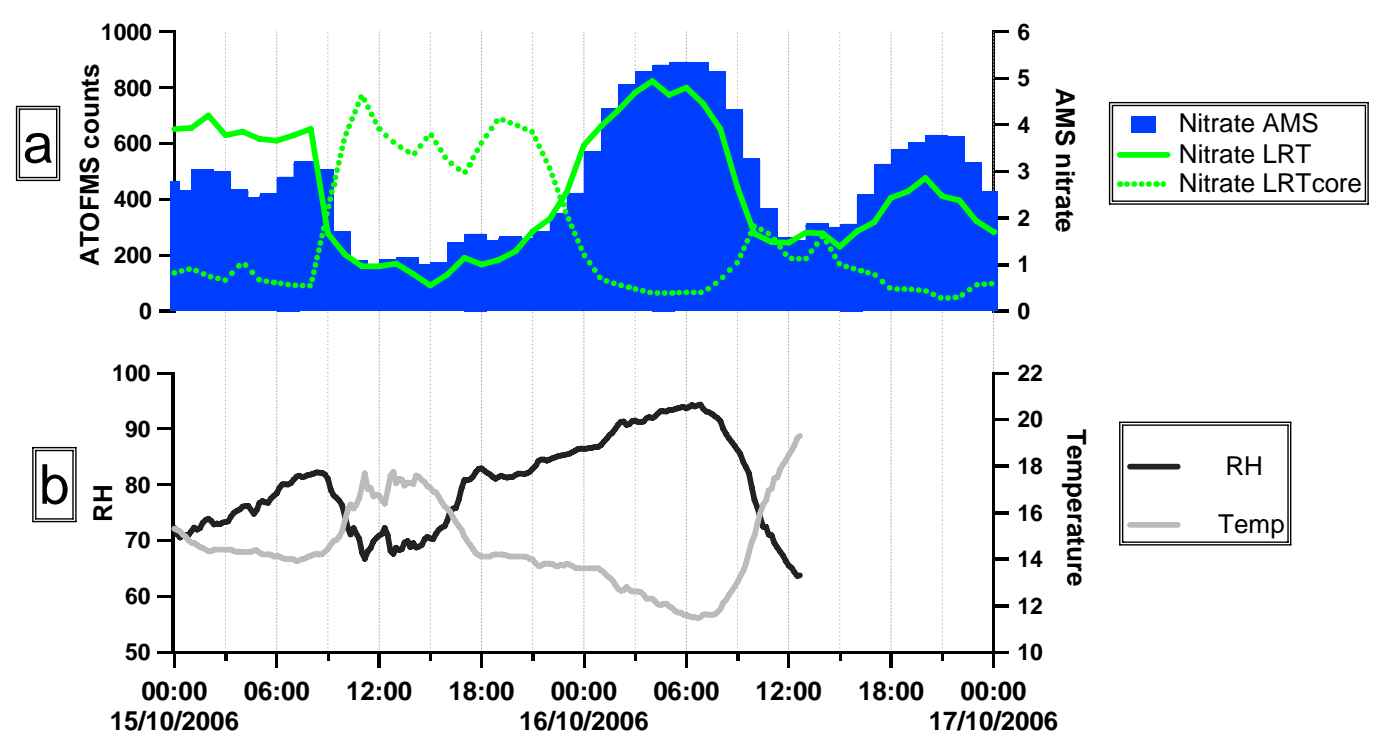

Fig. 6. (a) AMS mass loading $\left(\mu \mathrm{g} / \mathrm{m}^{3}\right)$ for nitrate and ATOFMS LRT nitrate temporal trends (1 h resolution) and (b) Relative Humidity and Temperature profiles. $\left(\%\right.$ and ${ }^{\circ} \mathrm{C}$, respectively.)

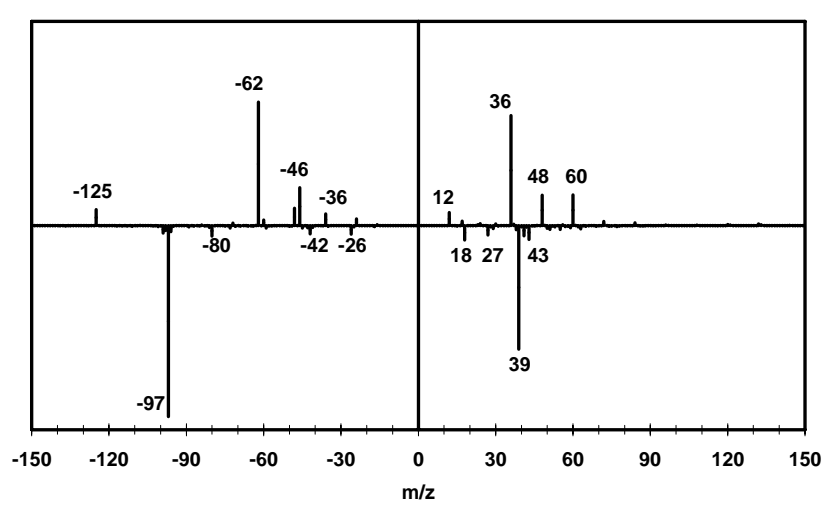

Fig. 7. Positive and negative ART-2a spectral differences for LRT Nitrate minus LRT Nitrate core. Peaks above the horizontal line represent components less abundant in the core than the LRT nitrate; below the line are those with greater abundance.

$250 \mathrm{~nm}$. It is likely that because their dimensions, the whole of the particles was ablated by the LDI process. The full chemical quantification of bigger particles is more challenging, since the whole particle is not always fully ionized. The matrix effect of Elemental-Organic carbon signature in particles as big as the LRT nitrate has not been fully investigated, and it could be one reason for the unexpectedly stronger elemental carbon signature associated with the LRT nitrate.

Figure $2 b$ shows that the ATOFMS sampled a much larger number of the locally formed nitrate particle type during the period characterised by air masses which had previously travelled over Europe, especially during the second period (14-19 October). Air mass back trajectories were broadly similar over the period 14-18 October 2006, indicating air masses arriving from mainland Europe. PM levels increased over this period (Fig. 1), suggesting a build-up of aerosols resulting from a high pressure system centred over the Baltic Sea and extending of much of northern Europe. This gave rise to poor vertical mixing of pollution and a slow flow of air from the east towards the UK. Subsequently, passage of a front brought westerly air masses towards the UK (as the five day air masses back trajectories of 19 October 2006 revealed), significantly reducing the PM (Fig. 1). Air mass back trajectories and PM daily concentrations show that aerosol increased throughout the period 14-18 of October, reflecting the slow-moving continental air masses.

Two qualitative aspects of the period 14-18 of October should be noted in relation to Fig. 2b. Firstly, the diurnal variation for the LRT nitrate particle type (expressed as ATOFMS particle number difference between day time - 08:00/20:00 and night time - 20:00/08:00) was about twice that of the local nitrate, possibly suggesting the higher volatility of the LRT nitrate compared to that produced locally. This is hard to explain, but is probably a compositional effect. Alternatively, if the core of the local nitrate type is more abundant during daytime due to local emissions, the nitrate may spread across more particles, with a similar number being classified as local nitrate type during day and night, despite lesser nitrate overall during daytime.

The second aspect of Fig. $2 \mathrm{~b}$ is that the ratio between LRT nitrate and local nitrate varies during the period 14th-18th 


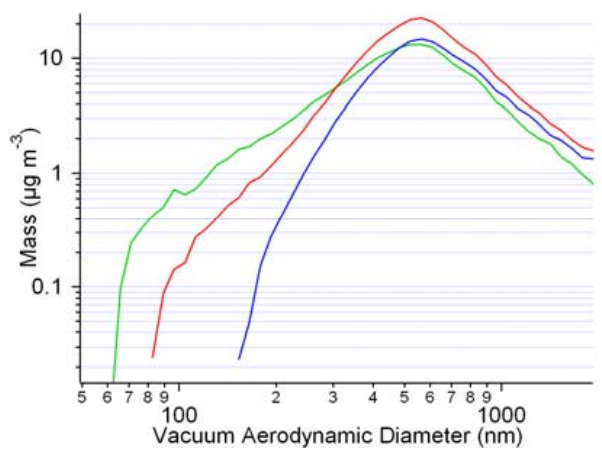

(a)

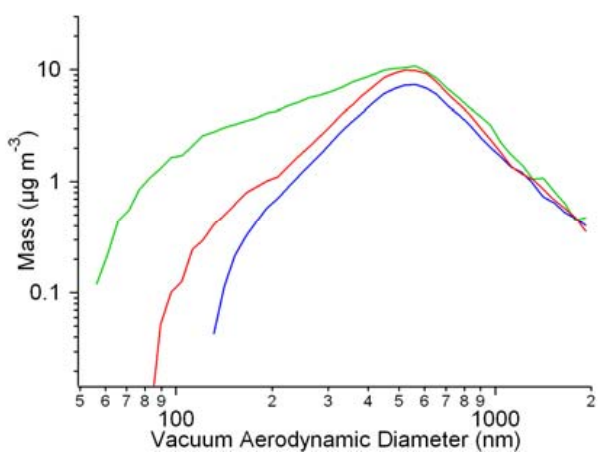

(c)

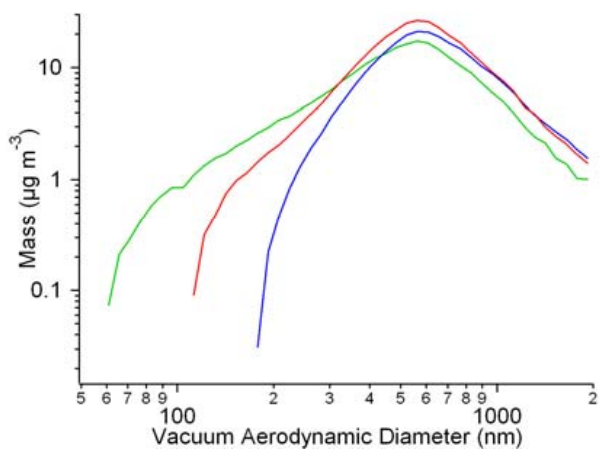

(b)

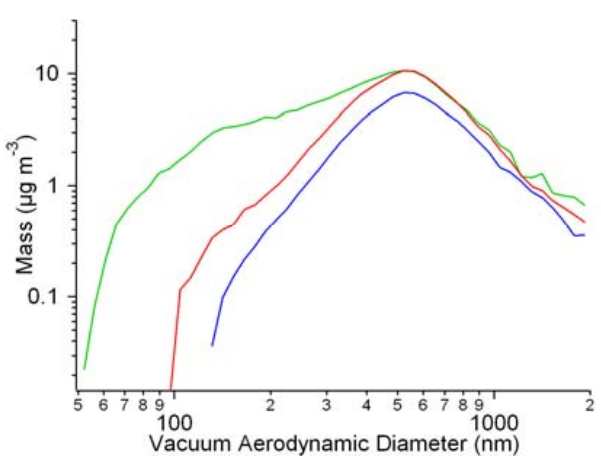

(d)

Fig. 8. Average size-resolved AMS mass loading $\left(\mu \mathrm{g} / \mathrm{m}^{3}\right)$ for total organic (green), sulphate (red) and nitrate (blue) for the same nocturnal period (23:00-06:00) on days (a) 14 (b) 15, (c) 17 and (d) 18 October 2006.

of October. Whilst the ratio between ATOFMS LRT nitrate and ATOFMS local nitrate was about 4 during 14 and 15 October, it dropped to less than 1 on 17 and 18 October. This finding suggests that part of the nitric acid evaporated from the regionally transported LRT particle nitrate could have condensed subsequently to form the local nitrate particle type. However, further studies need to be carried out in order to validate this hypothesis. Data from the AMS seems to support this theory. Figure 8 shows the AMS sizeresolved aerosol mass loading for four different periods of time during the evolution of the regionally transported air masses, from 14 through to 18 October. Each figure represents the average AMS mass loading taken for the same period of $7 \mathrm{~h}$ during nighttime (23:00-06:00) for different days (14, 15, 17 and 18 October). The AMS data are consistent with the ATOFMS local nitrate / LRT nitrate ratios. A higher fraction of fine aerosol nitrate mass loading below $300 \mathrm{~nm}$ can be seen during periods of higher ATOFMS local nitrate detection on the 17 and 18 October in comparison to the 14 and 15 . In other words, the progressively higher concentra- tions of fine nitrate aerosol detected in the period 17-18 (relative to days 14-15) may support the idea that part of the nitric acid lost by the LRT type would form the local nitrate particle type over the period 14-18 October. Figure 9 shows the result of calculating nitric acid uptake rates to particles in the size ranges typical of the local nitrate and LRT nitrate particle types. The condensational loss rate, $\mathrm{K}_{t}$, is calculated following Schwartz (1986). A value for the uptake coefficient (gamma) of 0.03 has been used, although use of a value of 0.1 makes little difference to the relative rates. This shows that the rates are broadly similar, except in the period 14-18 October, when uptake by larger LRT nitrate particles is more favourable. Nonetheless, this shows that uptake of nitric acid vapour by both particle types was occurring (assuming equal uptake coefficients) and that nitric acid evaporated from one particle type could readily transfer to the other when conditions favoured condensation. 


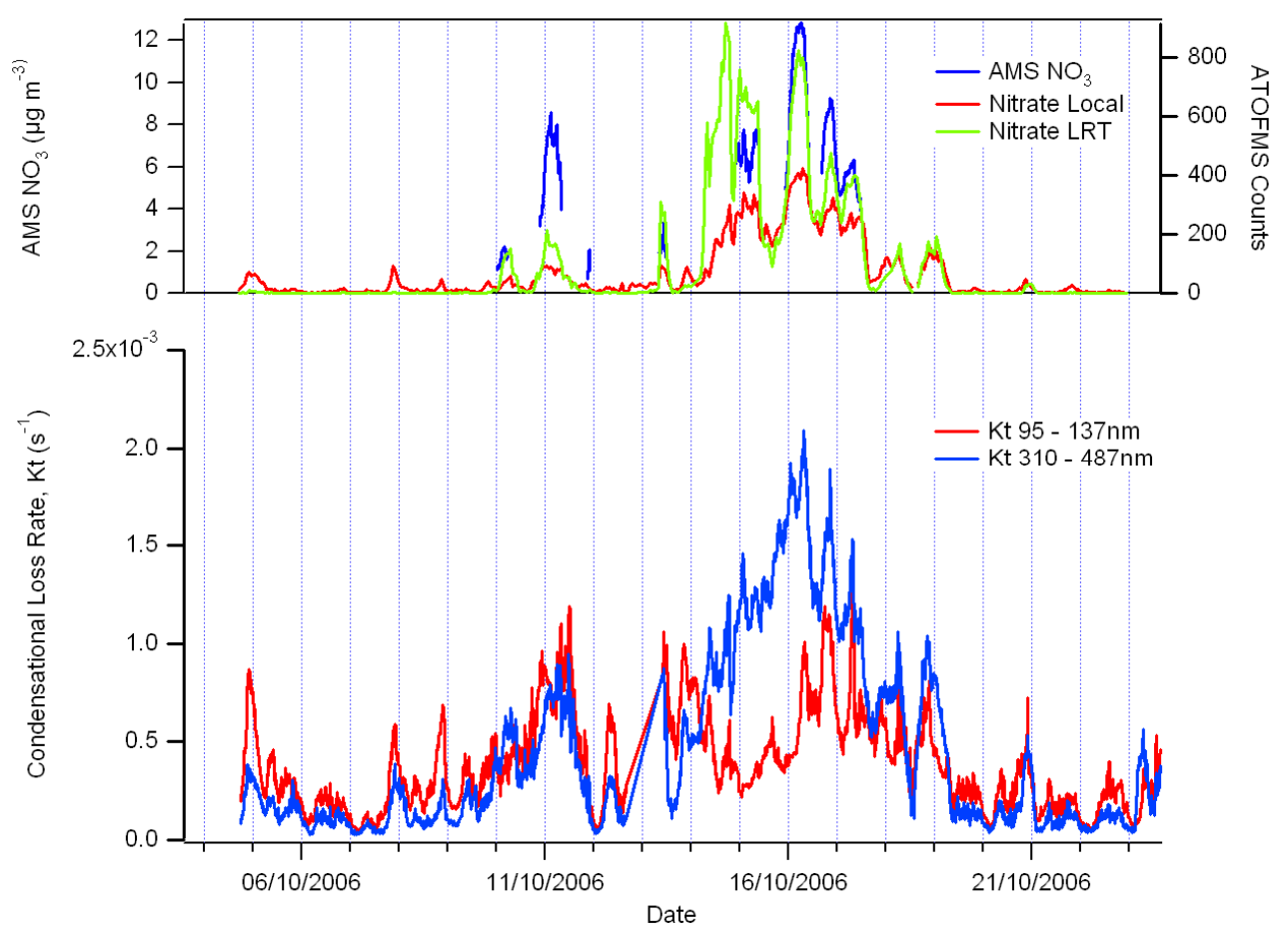

Fig. 9. The top graph shows the total nitrate mass as measured by the AMS and the number of detected particles for Nitrate Local and Nitrate LRT from the ATOFMS. The bottom graph shows the condensational loss rate for two sizes ranges using the DMPS data, as calculated according to the method of Schwartz (1986).

The results presented in this paper can be linked to other measurements made during the REPARTEE-1 campaign, specifically:

1. Simultaneous measurements of nitrate at the Park and at the London Telecom Tower at $180 \mathrm{~m}$ elevation by lowvol sampler suggest that there was an overall deposition gradient of total nitrate (including $\mathrm{NaNO}_{3}$ ) above the city (Nemitz et al., 2009).

2. Small non-refractory nitrate (i.e. $\mathrm{NH}_{4} \mathrm{NO}_{3}$ only) emission fluxes (preliminary figure: $47 \mathrm{ng} \mathrm{m}^{-2} \mathrm{~s}^{-1}$ ) were measured with an Q-AMS eddy-covariance setup above the city (Thomas, 2008).

Together these two observations support the view that most of the Local Nitrate is probably formed from the fraction evaporated from the LRT Nitrate, but also that some of the Local Nitrate represents new nitrate formation, consistent with the urban nitrate increment identified in earlier studies.

\section{Summary and conclusions}

This study has shown for the first time the real time detection of two different types of nitrate aerosols. The first is characterised by small particles, peaking in the smallest detectable ATOFMS size at $200 \mathrm{~nm}$. They were formed locally within the urban London area, during nighttime (23:00-06:00). The AMS supports the ATOFMS finding, by showing half of the nitrate aerosol loading (detected during the same time period) distributed in particle sizes smaller than $350 \mathrm{~nm}$.

The second nitrate particle type is characterised by larger particles, peaking in the accumulation mode at about $600 \mathrm{~nm}$. This type of nitrate detected in London has been regionally transported from continental Europe. It is internally mixed with sulphate, ammonium and both elemental and organic carbon. The nitrate (and likely the ammonium) part is very volatile, going into the gas phase during the day and leaving a core of about $300 \mathrm{~nm}$ mainly composed also of sulphate, elemental and organic carbon.

Local nitrate was found to peak on most nights during the first part of the field study, but after dawn it disappeared. The reasons are multiple and include increasing temperature (and consequent volatilisation), but also the increasing wind speed and the increasing urban boundary layer depth during the day (and consequent advection and vertical mixing).

During regional transport of pollution, the oxidised nitrogen content of the air is enhanced. During the day, under warm conditions the equilibrium between gaseous and particulate nitrate favours the gas phase. At night, cooler temperatures and higher humidities favour partitioning to the particulate phase. As these air masses pass over London fresh emissions of particulate matter change the particle population and hence at nighttime the nitrate condenses across 
both populations of particles, processing the fresh particulate matter. In addition, $\mathrm{NO}_{\mathrm{x}}$ is emitted over the urban airshed and can form nitrate rapidly through $\mathrm{NO}_{3}$ and $\mathrm{N}_{2} \mathrm{O}_{5}$. This rapid conversion enhances the available nitrate and may add significantly to the nitrate available for condensation, enhancing night-time concentrations compared to those observed in the day. The role of the $\mathrm{NO}_{3}$ radical pathway compared to daytime processing of $\mathrm{NO}_{2}$ by $\mathrm{OH}$ in particulate nitrate formation needs to be quantified.

Acknowledgements. This research was supported by the UK Natural Environment Research Council as part of the programme of the National Centre for Atmospheric Science and through the City Flux project. The authors are grateful also to the BOC Foundation for financial support of campaign expenses and to British Telecom and the Royal Parks for facilitating access to measurement sites. The assistance of Alistair Thorpe in the field measurements is also gratefully acknowledged.

Edited by: E. Nemitz

\section{References}

Abdalmogith, S. S. and Harrison R. M..: An analysis of spatial and temporal properties of daily sulphate, nitrate and chloride concentrations at UK urban and rural sites, J. Environ. Monitor., 8, 691-699, 2006a.

Abdalmogith, S. S., Harrison, R. M., and Derwent, R. G.: Particulate sulphate and nitrate in southern England and Northern Ireland during 2002/3 and its formation in a photochemical trajectory model, Sci. Total. Environ., 368, 769-780, 2006 b.

Abdalmogith, S. S. and Harrison, R. M.: The use of trajectory cluster analysis to examine the long-range transport of secondary inorganic aerosol in the UK, Atmos. Environ., 39, 6686-6695, 2005.

Adams, P. J., Seinfeld, J. H., Koch, D., Mickley, L., and Jacob, D.: General circulation model assessment of direct radiative forcing by the sulfate-nitrate-ammonium-water inorganic aerosol system, J. Geophys. Res.-Atmos., 106(D1), 1097-1111, 2001.

Alfarra, M. R., Coe, H., Allan, J. D., Bower, K. N., Boudries, H., Canagaratna, M. R., Jimenez, J. L., Jayne, J. T., Garforth, A. A., Li, S. M., and Worsnop, D. R.: Characterization of urban and rural organic particulate in the lower Fraser valley using two aerodyne aerosol mass spectrometers, Atmos. Environ., 38(34), 5745-5758, 2004.

Allan, J. D., Alfarra, M. R., Bower, K. N., Williams, P. I., Gallagher, M. W., Jimenez, J. L., McDonald, A. G., Nemitz, E., Canagaratna, M. R., Jayne, J. T., Coe, H., and Worsnop, D. R.: Quantitative sampling using an aerodyne aerosol mass spectrometer: 2. Measurements of fine particulate chemical composition in two UK cities (108, 4091, 2003), J. Geophys.Res.-Atmos., 108(D9), 4091, doi:10.1029/2002JD002359, 2003.

Allan, J. D., Coe, H., Bower, K. N., Alfarra, M. R., Delia, A. E., Jimenez, J. L., Middlebrook, A. M., Drewnick, F., Onasch, T. B., Canagaratna, M. R., Jayne, J. T., and Worsnop, D. R.: Technical note: Extraction of chemically resolved mass spectra from aerodyne aerosol mass spectrometer data, J. Aerosol Sci., 35, 909922, 2004.
Allen, A. G., Harrison, R. M., and Erisman, J. W.: Field measurements of the dissociation of ammonium nitrate and ammonium chloride aerosols, Atmos. Environ., 23, 1591-1599, 1989

Bauer, S. E., Koch, D., Unger, N., Metzger, S. M., Shindell, D. T., and Streets, D. G.: Nitrate aerosols today and in 2030: a global simulation including aerosols and tropospheric ozone, Atmos. Chem. Phys., 7, 5043-5059, 2007,

http://www.atmos-chem-phys.net/7/5043/2007/.

Bouwman, A. F., Lee, D. S., Asman, W. A. H., Dentener, F. J., VanderHoek, K. W., and Olivier, J. G. J.: A global highresolution emission inventory for ammonia, Global Biogeochem. Cy., 11(4), 561-587, 1997.

Brown, S. S., Ryerson, T. B., Wollny, A. G., Brock, C. A., Peltier, R. Sullivan, A. P., Weber, R. J., Dube, W. P., Trainer, M., Meagher, J. F., Fehsenfeld, F. C., and Ravishankara, A. R.: Variability in nocturnal nitrogen oxide processing and its role in regional air quality, Science, 311(5757), 67-70, 2006.

Canagaratna, M. R., Jayne, J. T., Jimenez, J. L., Allan, J. D., Alfarra, M. R., Zhang, Q., Onasch, T. B., Drewnick, F., Coe, H., Middlebrook, A., Delia, A., Williams, L. R., Trimborn, A. M., Northway, M. J., DeCarlo, P. F., Kolb, C. E., Davidovits, P., and Worsnop, D. R.: Chemical and microphysical characterization of ambient aerosols with the aerodyne aerosol mass spectrometer, Mass Spectrom. Rev., 26(2), 185-222, 2007.

Carslaw, N., Carpenter, L., Plane, J. M. C., Allan, B., Burgess, R. A., Clemitshaw, K. C., Coe, H., and Penkett, S. A.: Simultaneous measurements of nitrate and peroxy radicals in the marine boundary layer, J. Geophys. Res., 102, (D15), 18917-18933, 1997.

Carson, P. G., Johnston, M. V., and Wexler, A. S.: Laser desorption/ionization of ultrafine aerosol particles, Rapid Commun. Mass Sp., 11(9), 993-996, 1997.

Charron, A., Harrison, R. M., and Quincey, P.: What are the sources and conditions responsible for exceedences of the $24 \mathrm{~h} \mathrm{PM}_{10}$ limit value $(50 \mu \mathrm{g} \mathrm{m}-3)$ at a heavily trafficked London site?, Atmos. Environ., 41(9), 1960-1975, 2007.

Cozic, J., Verheggen, B., Mertes, S., Connolly, P., Bower, K., Petzold, A., Baltensperger, U., and Weingartner, E.: Scavenging of black carbon in mixed phase clouds at the high alpine site Jungfraujoch, Atmos. Chem. Phys., 7, 1797-1807, 2007, http://www.atmos-chem-phys.net/7/1797/2007/.

Crane, R. I. and Evans, R. L.: Inertial deposition of particles in a bent pipe, J. Aerosol Sci., 8, 161-170, 1977.

Crosier, J., Allan, J. D., Coe, H., Bower, K. N., Formenti, P., and Williams, P. I.: Chemical composition of summertime aerosol in the Po Valley (Italy), northern Adriatic and Black Sea, Q. J. Roy. Meteor. Soc., 133, 61-75, 2007.

Cross, E. S., Slowik, J. G., Davidovits, P., Allan, J. D., Worsnop, D. R., Jayne, J. T., Lewis, D. K., Canagaratna, M., and Onasch, T. B.: Laboratory and ambient particle density determinations using light scattering in conjunction with aerosol mass spectrometry, Aerosol Sci. Tech., 41(4), 343-359, 2007.

Dall'Osto, M. and Harrison, R. M.: Chemical characterisation of single airborne particles in Athens (Greece) by ATOFMS, Atmos. Environ., 40, 7614-7631, 2006.

Dall'Osto, M., Harrison, R. M., Coe, H., and Williams, P.: Realtime secondary aerosol formation during a fog event in London, Atmos. Chem. Phys., 9, 2459-2469, 2009, http://www.atmos-chem-phys.net/9/2459/2009/.

Draxler, R. R. and Rolph, G. D.: HYSPLIT (Hybrid Single-Particle 
Lagrangian Integrated Trajectory) model access via NOAA ARL READY website (http://www.arl.noaa.gov/ready/hysplit4.html), NOAA Air Resources Laboratory, Silver Spring, MD.

Drewnick, F., Hings, S. S., DeCarlo, P., Jayne, J. T., Gonin, M., Fuhrer, K., Weimer, S., Jimenez, J. L., Demerjian, K. L., Borrmann, S., Worsnop, D. R.: A new Time-of-Flight Aerosol Mass Spectrometer (TOF-AMS) - instrument description and first field deployment, Aerosol Sci. Tech., 39, 637-658, 2005.

Hallquist, M., Stewart, D. J., Stephenson, S. K., and Cox, R. A.: Hydrolysis of $\mathrm{N}_{2} \mathrm{O}_{5}$ on sub-micron sulfate aerosols, Phys. Chem. Chem. Phys., 5(16), 3453-3463, 2003.

Harrison, R. M., Jones, A. M. and Lawrence, R. G.: A pragmatic mass closure model for airborne particulate matter at urban background and roadside sites, Atmos. Environ., 37(35), 4927-4933, 2003.

Harrison, R. M., Jones, A. M., and Lawrence, R. G.: Major component composition of $\mathrm{PM}_{10}$ and $\mathrm{PM}_{2.5}$ from roadside and urban background sites, Atmos. Environ., 38(27), 4531-4538, 2004.

Jayne, J. T., Leard, D. C., Zhang, X. F., Davidovits, P., Smith, K. A., Kolb, C. E., and Worsnop, D. R.: Development of an aerosol mass spectrometer for size and composition analysis of submicron particles, Aerosol Sci. Tech., 33(1-2), 49-70, 2000.

Liao, H., Chen, W. T., and Seinfeld, J. H.: Role of climate change in global predictions of future tropospheric ozone and aerosols, J. Geophys. Res.-Atmos., 111(D12), D1230, doi:10.1029/2005JD006852, 2006.

Liao, H., Seinfeld, J. H., Adams, P. J., and Mickley, L. J.: Global radiative forcing of coupled tropospheric ozone and aerosols in a unified general circulation model, J. Geophys. Res.-Atmos., 109(D16), D24204, doi:10.1029/2004JD005476, 2004.

Mansoori, B. A., Johnston, M. V., and Wexler, A. S.: Quantitation of ionic species in single microdroplets by online laser desorption/ionization, Anal. Chem., 66(21), 3681-3687, 1994.

Matthew, B. M., Middlebrook, A. M., and Onasch, T. B.: Collection efficiencies in an Aerodyne Aerosol Mass Spectrometer as a function of particle phase for laboratory generated aerosols, Aerosol Sci. Tech., 42(11), 884-898, 2008.

Mentel, T. F., Sohn, M., and Wahner, A.: Nitrate effect in the heterogeneous hydrolysis of dinitrogen pentoxide on aqueous aerosols, Phys. Chem. Chem. Phys., 1(24), 5451-5457, 1999.

Murphy, D. M.: The design of single particle laser mass spectrometers, Mass Spectrom. Rev., 26(2), 150-165, 2007.

Nemitz, E., Phillips G. J., Dall'Osto, M., Harrison, R. M., Williams, P. I., and Coe, H.: Concentrations and Fluxes of Inorganic Reactive Gases and Aerosols above London, Atmos. Chem. Phys. Discuss., in preparation, 2009.

Noble, C. A. and Prather, K. A.: Real-time single particle mass spectrometry: A historical review of a quarter century of the chemical analysis of aerosols, Mass Spectrom. Rev., 19(4), 248274, 2000.

Qin, X. Y., Bhave, P. V., and Prather, K. A.: Comparison of two methods for obtaining quantitative mass concentrations from aerosol time-of-flight mass spectrometry measurements, Anal. Chem., 78(17), 6169-6178, 2006.
Petzold, A. and Schonlinner, K.: Multi-angle absorption photometry - a new method for the measurement of aerosol light absorption and atmospheric black carbon, Aerosol Sci., 35, 421-441, 2004.

Pui, D. Y. H., Romay-Novas, F., and Liu, B. Y. H.: Experimental study of particle deposition in bends of circular cross section, Aerosol Sci. Tech., 7, 301-15, 1987.

Rebotier, T. P. and Prather, K. A.: Aerosol time-of-flight mass spectrometry data analysis: A benchmark of clustering algorithms, Anal. Chim. Acta, 585(1), 38-54, 2007.

Reilly, P. T. A., Lazar, A. C., Gieray, R. A., Whitten, W. B., and Ramsey, J. M.: The elucidation of charge-transfer-induced matrix effects in environmental aerosols via real-time aerosol mass spectral analysis of individual airborne particles, Aerosol Sci. Tech., 33(1-2), 135-152, 2000

Schoolcraft, T. A., Constable, G. S., Jackson, B., Zhigilei, L. V., and Garrison, B. J.: Molecular dynamics simulations of laser disintegration of amorphous aerosol particles with spatially nonuniform absorption, Nucl. Instrum. Meth. A, 180, 245-250, 2001.

Silva, P. J. and Prather, K. A.: Interpretation of mass spectra from organic compounds in aerosol time-of-flight mass spectrometry, Anal. Chem., 72(15), 3553-3562, 2000.

Silva, P. J., Vawdrey, E. L., Corbett, M., and Erupe, M.: Fine particle concentrations and composition during wintertime inversions in Logan, Utah, USA, Atmos. Environ., 41(26), 54105422, 2007.

Song, X. H., Hopke, P. K., Fergenson, D. P., and Prather, K. A.: Classification of single particles analyzed by ATOFMS using an artificial neural network, ART-2A, Anal. Chem., 71(4), 860-865, 1999.

Spencer, M. T., Shields, L. G., Sodeman, D. A., Toner, S. M., and Prather, K. A.: Comparison of oil and fuel particle chemical signatures with particle emissions from heavy and light duty vehicles, Atmos. Environ., 40(27), 5224-5235, 2006.

Suess, D. T. and Prather, K. A.: Mass spectrometry of aerosols, Chem. Rev., 99(10), 3007-3035, 1999.

Thomas, R. M.: Measurement of Speciated Aerosol Fluxes, PhD thesis, University of Manchester, 2007.

Thomson, D. S., Middlebrook, A. M., and Murphy, D. M.: Thresholds for laser-induced ion formation from aerosols in a vacuum using ultraviolet and vacuum-ultraviolet laser wavelengths, Aerosol Sci. Tech., 26(6), 544-559, 1997.

Williams, P. I., Gallagher, M. W., Choularton, T. W., Coe, H., Bower, K. N., and McFiggans, G.: Aerosol development and interaction in an urban plume, Aerosol Sci. Tech., 32(2), 120-126, 2000.

Yin, J. and Harrison, R. M.: Pragmatic mass closure study for $\mathrm{PM}_{1.0}, \mathrm{PM}_{2.5}$ and $\mathrm{PM}_{10}$ at roadside, urban background and rural sites, Atmos. Environ., 42(5), 980, 2008. 